\title{
Measuring Effectiveness of Telecom Regulation Using Perception Surveys ${ }^{1}$
}

\author{
Helani Galpaya², Rohan Samarajiva²,
}

\begin{abstract}
The Telecom Regulatory Environment (TRE) survey presented in this paper is a tool to evaluate the effectiveness of the Telecom Regulatory and Policy Environment of a country. It asks senior stakeholders to assess the effectiveness (efficacy) of the regulatory and policy environment in the telecom sector of a country along seven dimensions. The dimensions are based on the General Agreement for Trade in Services (GATS) regulatory reference paper on telecommunications, with some additions. Three telecom subsectors of fixed, mobile and broadband are evaluated separately. The evaluation is done on a Likert scale of one to five. The stakeholders are selected to represent in a balanced manner those directly affected by regulation and policy (such as operators and equipment manufacturers), those observing the sector with broader interest and affected by its overall performance (such as lawyers, consultants, investment analysts) and those representing consumer interests (such as civil society organizations, other government institutions). Equal weight is given to each sub-group of stakeholders in order to ensure that a range of views are represented in the final score.
\end{abstract}

The results can be used to diagnose the positives and negatives of a country's regulatory environment. When multiple countries are surveyed, resulting comparisons can give insight into best or worst practices and act as tool for leaning. For investors who are evaluating investment options in multiple countries, the TRE scores can act as a proxy indicator for regulatory risk.

The paper surveys the literature on measuring regulatory performance in infrastructure sectors, describes the TRE methodology and discusses the results from implementing the survey in 2006 and 2008 in a number of South and South East Asian countries.

\subsection{Introduction: Measuring regulatory effectiveness}

Networked infrastructure industries such as electricity, telecommunications and water have historically been subject to regulatory oversight. Certain characteristics of these sectors (such as extensive

\footnotetext{
${ }^{1}$ This research has been funded through a grant from the International Development Research Center (Canada) and the Department for International Development (UK). The authors also acknowledge the contribution of the research team that helped refine the methodology, implement TRE surveys and synthesize results in various countries. This team (over the years) has included Payal Malik (India), Malathy KnightJohn (Sri Lanka), Deunden Nikomborirak (Thailand), Divakar Goswami (Indonesia), Chanuka Wattegama (Indonesia), Joseph Wilson (Pakistan), Erwin Alampay (Philippines), M iraj Khaled (Bangladesh), Lorraine Carlos Salazar (Philippines). Important contributions made by Divakar Goswami, Sriganesh Lokanathan and Dimuthu Ratnadiwakara in refining and critiquing the methodology are also gratefully acknowledged.

2 helani@lirneasia.net, $\mathrm{COO}$ and Indicator Specialist, LIRNEasia

3 rohan@ lirneasia.net, Chairman and CEO, LIRNEasia
} 
economies of scale and scope, large sunk costs relative to fixed and variable components, and provision of services deemed essential) have necessitated and justified regulatory action in order to ensure consumer welfare as well as to encourage private-sector participation. These sectors which were government-owned integrated monopolies in many countries have undergone significant changes through institutional reforms that include vertical and horizontal restructuring, privatization and the establishment of effective regulation. Though experience has varied considerably across countries and sectors, as Kessides (2004) summarizes, for the most part reforms have significantly improved infrastructure performance, as measured by increased investment (leading to increased coverage), service quality, productivity, cost effectiveness and prices that are more closely aligned with underlying costs. The actions of the regulator after such reforms have taken place are also important. These factors are true in developed as well as developing countries. For example, Fink et al (2002) study of 86 developing countries across Africa, Asia, Middle East, Latin America and the Caribbean show that competition, independent regulation and privatization (and the correct sequencing of these actions) produced the most positive effects.

Given the importance of regulatory and policy action in the performance of networked infrastructure industries, significant attention is paid to measuring the impact of such regulation. The literature that analyzes, quantifies and compares the impacts of regulation on networked infrastructure industries is therefore substantive, with contributions made by the traditional academic disciplines and researchers within multilateral donor agencies (the latter's presence in the literature is not surprising because these institutions are involved in funding regulatory reform in numerous countries). Later in the paper we will situate the TRE in relation to other methods for evaluating regulatory effectiveness by scanning the current literature. But first, we describe the TRE methodology and describes how it is implemented.

\subsection{The TRE methodology}

The TRE provides measure of stakeholder perception of a country's regulatory environment. The TRE instrument/survey asks informed stakeholders to rate (on a Likert scale of 1 to 5, 1 being highly unsatisfactory, 5 being highly satisfactory) the Telecom Regulatory and Policy Environment in a country along 7 dimensions.

Seven Dimensions: The seven dimensions are the regulation of the following: market entry, allocation of scarce resources, anti competitive behavior, interconnection, tariff regulation, universal service obligations and quality of service. Five of the seven dimensions are based on the GATS (General Agreement for the Trade in Services) reference paper on telecommunications, the widest consensus globally on what constitutes "good regulation" and adopted by over 80 countries.

Three telecom sub-sectors: The three sub-sectors of telecom - mobile, fixed and broadband - are evaluated separately. In other words, the stakeholders are asked to evaluate the effectiveness of the regulatory environment as applicable to the fixed telephony sector along 7 dimensions, the mobile sector along 7 dimensions, and the broadband sector along seven dimensions. So a total of 21 responses are requested from each respondent 
Three categories of survey respondents: The respondents to the survey fall into 3 different categories:

- Category 1: those directly involved in the sector such as operators, equipment vendors.

- Category 2: those indirectly impacted by the sector or those studying and those observing the sector with broader interest such as consultants and lawyers.

- Category 3: those who represent the broader public interest such as media personnel, other government officials, former regulators and staff, and civil society organizations.

Current telecom regulators and telecom policy makers are not surveyed because the goal is not to obtain a self-evaluation, but to evaluate how those impacted by the regulators and policy makers feel.

Number of respondents: The larger the number of respondents, the less biased the survey. However, the goal of the TRE is to measure perception among informed stakeholders, those who have expert, indepth_knowledge about (or first-hand experience in dealing with and navigating) the various aspects of the regulatory and policy environment in a given country. Therefore the pool of potential respondents is limited to the senior level decision makers in various organizations. For example for Category 1 , questionnaires are only sent to (and responses only accepted from) CxO level employees (e.g. Chief Executive Officers, Chief Regulatory Officers, Chief M arketing Officers, etc) at telecom operators or equipment manufacturers. If a team of consultants were hired by the regulator, the team leader is the ideal potential respondent in Category 2. While such respondents do provide more knowledgeable set of responses, they are few in number. But in order to minimize bias within a Category and across the whole, a minimum number of responses have been specified, and without meeting this minimum the TRE survey is considered incomplete. The minimum number of responses per category is 15 , resulting in a minimum of 45 responses being required per country. Our experience from implementing TRE surveys in 2006 and 2008 (in 6 and 9 Asian countries, respectively) shows that this is a reasonable target, achievable by a researcher or a research organization with a sufficiently prominent profile within the country. For micro-states (those with less than 1 million population), the above target is impossible. Therefore the minimum acceptable per category is 5 responses and minimum per country is 15 . Experience in surveying the Maldives (population of 300,000, duopoly in each of the 3 sectors fixed, mobile and broadband) in 2008 showed it was possible though extremely difficult (specially if the rule of only surveying CEOs of the operators is followed).

Equal weight to each respondent category: The stakeholders have different incentive structures, and will therefore have differing opinions of whether specific regulatory actions are "good", since what is suitable to one party (say, companies) may not be suitable to others (say, consumers). Yet in order keep the result as objective as possible and to avoid over-representing one point of view, each respondent category should contribute equally to the final TRE score. However in these types of surveys it is not possible to control how many completed questionnaires will be returned by respondents in each category. Therefore statistical weighting is used to equalize the contributions made by each category.

Administering the survey: The survey (consisting of 21 statements/questions, and space for option comments) is administered through multiple modes: via the internet, through personal meetings, through mail or fax. All responses are confidential and anonymous (only the category of the respondent is recorded, for purposes of calculating above-mentioned weights and keeping track of minimum- 
number of response requirements). Attached to each survey is a listing of significant regulatory and policy events that took place in the past year, written in bland language. The purpose of this is to refresh the respondent's memory. The bland language is used to ensure the respondent is not positively or negatively influenced by the content. Surveys are carried out at the same time in multiple countries in order to ensure that cross-country comparisons can be done with least variations in external factors. A description of each dimension is also provided with each questionnaire. For example, Interconnection is described as and includes "Interconnection with a major operator should be ensured at any technically feasible point in the network. Quality of interconnection comparable to similar services offered by own network. Reasonable rates for interconnection. Unbundling of interconnection. Interconnection offered without delay. Sharing of incoming and outgoing IDD revenue. Payment for cost of interconnection links and switch interface. Payment for cost of technical disruption of interconnection".

The questionnaire, a sample of Significant Regulatory Events from an actual survey, and other documents used in the survey are given in Annex 1.

Desk Research and Interviews: In addition to the survey, interviews with experts (stakeholders) and a detailed review of the regulatory landscape (desk research) are done. This enables depth analysis of the TRE scores, in order to identify why scores for certain dimensions are low or high, why scores have changed from previous surveys and so on. Particular attention is paid if the regulatory actions and regulatory framework (as revealed by the desk research) are contradictory to the TRE Scores (e.g. legal rulings on tariff regulation may be reveal them to be "sound" and in keeping with international best practice, but TRE scores for tariff regulation are low). Reasons for such results may be varied - for example, the best-practice regulatory actions may have been taken recently and not yet made an impression on the stakeholders (perception is a measure of cumulative impression over a longer period of time), or the impact of regulatory action may not yet be visible to stakeholders (certain policy and regulatory changes do take time to impact the industry) and so on. The analyzed results are documented in a detailed country-report.

Using the TRE results (TRE scores): We believe the best use of TRE results (scores) is as a diagnostic tool, to identify which areas need attention. Country results, when compared historically, can also indicate improvements or declines over time of regulatory effectiveness.

As a rule, only aggregate scores per dimension are reported and the scores are not broken down further (e.g., by respondent category). For example, for a given country, the TRE score for Tariff Regulation is reported, even though that score is made up of the scores given by each of the 3 respondent categories. This is to further ensure confidentiality - in certain markets (often in those with a dominant incumbent, few new entrants and a new entrant and a politically charged regulatory environment), revealing Category-wise TRE scores may reveal (or strongly hint at) the identity of respondent or their firms. 
However, if a researcher is successful in obtaining a sufficiently large number of responses per category, disaggregation may be possible, and may provide for rich analysis ${ }^{4}$.

Another use of the TRE scores is to benchmark regulatory regimes in multiple countries. However, different biases may influence respondents in different countries when assigning scores, therefore comparing TRE scores across countries is less defensible, in theory. Yet, cross-country comparisons can be informative and useful as a learning tool. It can also help evaluate regulatory risk, and thereby help the decision making of investors who are examining several countries to invest in. While regulatory risk is not the only concern of investors, it is an important one. Potential investors will often engage in regulatory due-diligence which involves not just scanning the laws and regulations, but also interviews with local experts. The TRE can now quantify the relative regulatory risks in countries - ceteris paribus, a country with lower TRE scores in all dimensions poses lower regulatory risk than a country with higher TRE scores.

\subsection{Situating the TRE in literature on measuring regulatory effectiveness}

The literature on measuring regulatory effectiveness is rich and varied. The intent of this section is not to cover every study, but to scan the different approaches taken in various studies, to analyze the differences in their approaches along various dimensions (such as what they evaluate, whether objective or subjective data is used etc) and to identify how and where the TRE is similar or different. We also limit ourselves to the assessment of hard infrastructure industries/sectors ${ }^{5}$.

\subsection{What to assess - sector outputs or regulatory system?}

In theory, it is possible to take two completely different approaches to measuring effectiveness of regulatory actions. At one end of the spectrum, is the view that measuring sector performance (along varied dimensions such as increasing coverage, quality and choice and decreasing price) is the best or a sufficient proxy for regulatory performance. After all, if good regulation leads to good sector performance (and bad regulation leads to bad performance), the results of the regulator's effectiveness is ultimately reflected in a country's telecom sector's performance. Yet regulation is just one element that impacts sector performance. As Berg's (2000) detailed framework shows, industry conditions (including economies of scale and scope), market structure (including vertical integration), historical Experience and many other factors interact together to impact the regulatory system and sector performance. And as Levy and Spiller (1994) concluded, political institutions and economic conditions interact with, and have an impact on, regulatory processes. It may be possible for regulatory actions to be "good" or optimal (i.e. stand up to best practices in regulation when evaluated theoretically), but sector performance be bad, due to negating influence of the larger political or policy climate. The

\footnotetext{
${ }^{4}$ For example in 2006, over 100 responses were received in the Sri Lankan survey. With over $30+$ responses per category, disaggregation of the scores of each dimension by respondent category might have been feasible without compromising confidentiality

${ }^{5}$ If we were to expand our literature to include studies that evaluate any type of regulatory system (not just limited to infrastructure or hard/networked infrastructure), a good starting point is Berg's (2009) paper. It analyzes approaches taken by over 8 different studies to evaluate diverse regulatory systems. The TRE assessment is also one of the methodologies covered in his paper.
} 
converse (that regulatory actions are sub-par, but the sector itself performs well) is also possible. As is anything in between (for example three of the countries in Spiller and Levy's study function under "less than ideal" economic and political conditions, but are able to achieve results of good regulation because they at least able to constrain arbitrary administrative actions). Therefore at the other end of the spectrum is the view that regulatory action cannot simply be evaluated by looking at final sector performance, and that it needs to be done through a more insightful or different manner.

The TRE methodology is closer to this latter approach, in that it asks respondents to evaluate the overall regulatory environment. Note that depending on the country, some dimensions in the TRE (e.g., universal service obligations) may be under the purview of the policy maker, not the regulator. So in fact the TRE is an assessment of the regulatory and policy environment, not of the regulatory agency.

\subsection{Assessment Framework}

Various criteria or evaluation frameworks have been used by evaluators of regulatory regimes. Brown et al (2006) clearly point out that evaluation of both governance (the formal and informal processes involved in regulation, legal and institutional frameworks) and substance - (the content of actual regulatory decisions) are important. But in most popular studies, the framework focuses on criteria to evaluate regulatory governance. But on the positive side, there appears to be strong agreement among authors on what good regulatory governance entails - most emphasize clarity of assignment of functions, regulatory autonomy, accountability and transparency (Stern \& Cubbin, 2005). For example, a NERA (1998) study uses a framework consisting of six elements - clarity of roles and objectives, autonomy, participation, accountability, transparency and predictability - to assess the impact of governance and regulatory reforms in six Asian countries ${ }^{6}$. One year later, Stern and Holder (1999) used the same data set to further elaborate the evaluation framework (for example, separating the 6 criteria into formal/legal accountability and informal accountability). Noll's (2000) framework for evaluating regulatory governance includes some of the above components (accountability, transparency), but also include capacity and competency as well. The UK Better Regulation Task Force's principles of good regulation are a slight variation on the above - the criteria include transparency, accountability, proportionality, consistency and targeting.

The TRE Survey asks respondents if the country's regulatory system is effective along different dimensions, and describes very briefly the elements involved in each. It does not necessarily specify what "effective" means, at least not in any detail. Therefore it is up to the respondent to decide. It is likely that the responses are influenced by the respondents' experiences with and perceptions of both regulatory governance and substance. For example, consumer groups are unlikely to think a tariff order that increases prices is effective (substance), yet may think that a public consultation process that enabled their views to be heard as effective (process, part of regulatory governance).

\footnotetext{
${ }^{6}$ Performance of the chosen regulatory regime in a country can vary from and $A$ to $E$ or 1 to 5 (E being best possible performance and $A$ being the worst). For example, under the "clarity of roles and objectives", the sector receives an A if "no specification of any separate regulatory functions or responsibility is apparent, there is no primary law covering regulatory issues, and no effective distinction between policy and regulation" and receives an E if "the regulatory function is well articulated, well enshrined in primary legislation, and separated from the policy and commercial functions in practice".
} 
Above mentioned studies more-or-less converge on a similar framework - i.e., close agreement is reached by different researchers on what criteria constitute good regulatory governance. Such convergence is useful because the framework is then made usable to other researchers, who can apply it to different infrastructure sectors globally.

In contrast, the European Competitive Telecommunications Association's (ECTA) Regulatory Score Card for European Countries ${ }^{7}$ is designed to specifically evaluate regulatory effectiveness in the telecom sector in one region of the world. The ECTA Score Card assesses countries on adherence to the principals set out in the 2003 EU Communications Framework and associated guidelines and recommendations of the European Commission and European Regulators Group. The assessment is based on three components: 1) the overall institutional environment (scored out of 155 points), 2) the general market access conditions (scored out of 142 points) and 3) effectiveness of regulation and competitiveness in four key access markets and services (scored out of 189 points). It evaluates not just the regulator, but the broader environment - for example the first component (institutional framework) assess not just the regulator but also the legislator, dispute settlement body (if different from NRA) and appeal system. While the ECTA evaluation is comprehensive (the latest assessment contained 118 different aspects of the regulatory environment), its Euro-centric nature is likely to limit its application to a broader set of countries. This is because key evaluation criteria (and questions) such as "timely transposition of the EU regulatory framework" are only applicable to the EU where a common regulatory framework is found - a criteria not applicable in any other region so far ${ }^{8}$.

The TRE asks respondents to individually evaluate (by assigning a score between 1 and 5) seven different aspects or seven different dimensions of the regulatory environment are effective. Five of these dimensions (regulatory activity related to market entry, allocation of scarce resources universal service, interconnection, anticompetitive practices) are taken directly from the General Agreement for the Trade in Services (GATS) regulatory Reference Paper on telecommunications ${ }^{9}$. This document largely reflects "best practice" in telecoms regulation. More importantly, it is one that has been painstakingly negotiated and represents the broadest consensus on telecom regulation. At time of writing, 82 WTO member countries had signed up to the regulatory principles spelled out in it. The sixth dimension in the TRE is tariff regulation - added simply because regulating tariffs is one of the primary responsibilities of any telecom regulator, and because regulation of tariffs has a direct impact on sector stakeholders. As such, the 6 (of 7) dimensions of the TRE framework are applicable to most countries. We cannot claim that the seventh dimension (regulation of quality of service) is a global concern yet. It was added to the TRE framework in 2008 because regulators in Asia are finally paying attention to aspects of quality of service. It was a response to requests from regulatory agencies.

\footnotetext{
${ }^{7}$ See http://www.ectaportal.com/ en/basic651.html

${ }^{8}$ Note that ECTA is the trade body for telecom operators that compete with incumbent former monopolies. As such, the rankings have been disputed by ETNO (European Telecommunications Netw ork Operators association), the trade body representing incumbent operators (https:// publicaffairs.linx.net/news/?p=619). It has also been critiqued by some for being subjective in the manner in which weights are assigned and in the assessment of regulation in the key markets (Weeks and Williamson, 2006; Edwards and Waverman, 2006). Weeks and Williamson (2006) also critique the ECTA scorecard for conflating more regulation with effective regulation without considering the level of competition in the particular market

${ }^{9}$ See http://www.wto.int/english/tratop_e/serv_e/telecom e/tel23 e.htm
} 


\subsection{Evaluating Theory (what is written down) vs. Practice (what really happens)}

Researchers can examine the laws, regulations and orders related to a particular industry and make a conclusion about the effectiveness of the regulatory system. But what actually happens may be quite different to what it prescribed or intended in the rule (or indeed spirit) of the law. So at a minimum, many well-regarded studies will use (local) researchers or experts who have in-depth country knowledge. This is the approach taken by the NERA (1998) study mentioned earlier. The evaluation framework (and associated detailed questionnaire) are applied to each of the 12 sectors across the 6 countries by NERA staff who have previously worked in these countries, or local specialist advisors who worked with NERA staff (page 23, NERA, 1998). The questionnaire primarily focused on questions about the legal framework, but did contain questions that pointed towards practical implementation. Yet Stern and Cubbin (2005, page 15) conclude that because many of regulatory bodies studied were too newly established to have established to have enough of track record, "the results are heavily weighted to aspects of the law and legal obligations relative to actual regulatory practice". They also point out that "data based on analysis of laws without collection information on practice, are at best, seriously problematic; and, at worst, may be biased and misleading". A later study by the Prayas group (Prayas, 2003) mitigates such criticisms by first surveying regulators themselves (by sending out a questionnaire to the electricity regulators, covering such issues as regulatory staff and resources, use of consultants, transparency and participation. The information was further supplemented by examination of minutes from regulatory body meetings, scans of websites and so on. The resulting study highlights the difference between theory (well designed regulatory frameworks, established in the past with sufficient time to evolve) and practice (state governments and incumbent electricity companies working collusively to remove the treat of regulation, incumbents who resist providing data or provide wrong data, grossly inadequate staff resources and so on) to be quite significant.

The TRE is a survey of stakeholder opinion. But instead of surveying the opinions of regulators, it surveys the opinion of those directly or indirectly impacted by regulatory actions. The respondents fall into three categories that together represent the full spectrum of incentives that are found in the telecom sector. For example, Category 1 (those directly involved in service provision within the sector such as operators, equipment vendors equipment manufacturers) have incentive to maximize profits of individual firms. Within Category 1 , the incumbent's incentives may or may not be aligned with those of new entrants, depending on the situation. Category 3 (those who represent the broader public interest such as media personnel, other government officials, retired regulators, civil society organizations) will often have a very different opinions of what a good regulatory action is. By assigning equal weight to each of the three categories, the TRE attempts to ensure that the final assessment is not biased towards one point of view. By eliminating the level of subjectivity, we argue that the TRE provides a better assessment of a country's regulatory environment.

\subsection{Analysis of TRE scores form recent implementations of the TRE surveys}


The original TRE instrument was designed to assess regulatory effects on investment (Samarajiva \& Dokeniya, 2003). It proposed assessing 2 sectors (fixed and mobile) separately, along 5 dimensions. It was first piloted in 2005 in Sri Lanka (Samarajiva \& Dokeniya, 2005). After the pilot study, a sixth dimension was added and the survey was carried out in 6 countries (India, Pakistan, Sri Lanka, Indonesia, Philippines and Thailand) in 2006. The results have been documented in a paper by Samarajiva, et al. (2007).

Following detailed discussions with the multi-country research team in 2008, it was decided that a third sector (broadband) should be evaluated separately, and that another dimension (effectiveness of regulation of Quality of Service) should be added. The updated TRE survey was then implemented in 9 countries in the $3^{\text {rd }}$ quarter of 2008. Of the original 9 countries identified for the 2008 study, only 8 (India, Pakistan, Sri Lanka, M aldives, Bangladesh, Indonesia, Philippines and Thailand) were completed in time. Annex 1 provides the full set of results (TRE Scores) from 2008 survey.

In 2006 and 2008, detailed reports were written for each country surveyed. These reports (M alik, 2008; Wilson, 2008; Wattegama et al, 2008; Khaled, 2008; Knight-John, 2008; Galpaya, 2008; Alampay, 2008; Nikomborirak \& Cheevasittiyanon, 2008) analyze the results and give in-depth country-specific information.

The purpose of this section is not to repeat the analysis that is already done in the country papers, but to highlight the types of analysis that is possible with the TRE surveys. For example, the TRE studies are an effective method to identify best and worst practices across countries. They are also a good way to track how regulatory action (or inaction) is perceived by stakeholders over time. Several such examples are given below. The graphs shown are ordered by region (South Asian countries on the left, South East Asian on the right). Though the scores of $M$ aldives are presented in each cross-country graph, comparability of scores between M aldives and the other (much larger) markets is questionable. The respondents from the small island nation where most people know each other showed significant concerns during the survey. Even though the market is a duopoly and stakeholders express unhappiness during personal (private) interviews, on paper (in responding to the TRE survey), they rate each dimension of regulation as very effective (i.e. give high scores, close to 4 out of a possible 5 , and certainly higher than the midpoint of 3). For these reasons, though TRE scores for the M aldives are presented in the graphs below, they are visually marked with a gray colored box and are not used in the benchmarking or the identification of best and worst practices.

\subsection{Best and Worst Practices revealed through the TRE assessments}

\subsubsection{Market Entry}

The M arket Entry TRE scores reflect stakeholder perceptions about the conditions for entering and operating in the market. Transparency of licensing, ease of obtaining a license, barriers to entry and growth are included under M arket Entry. 


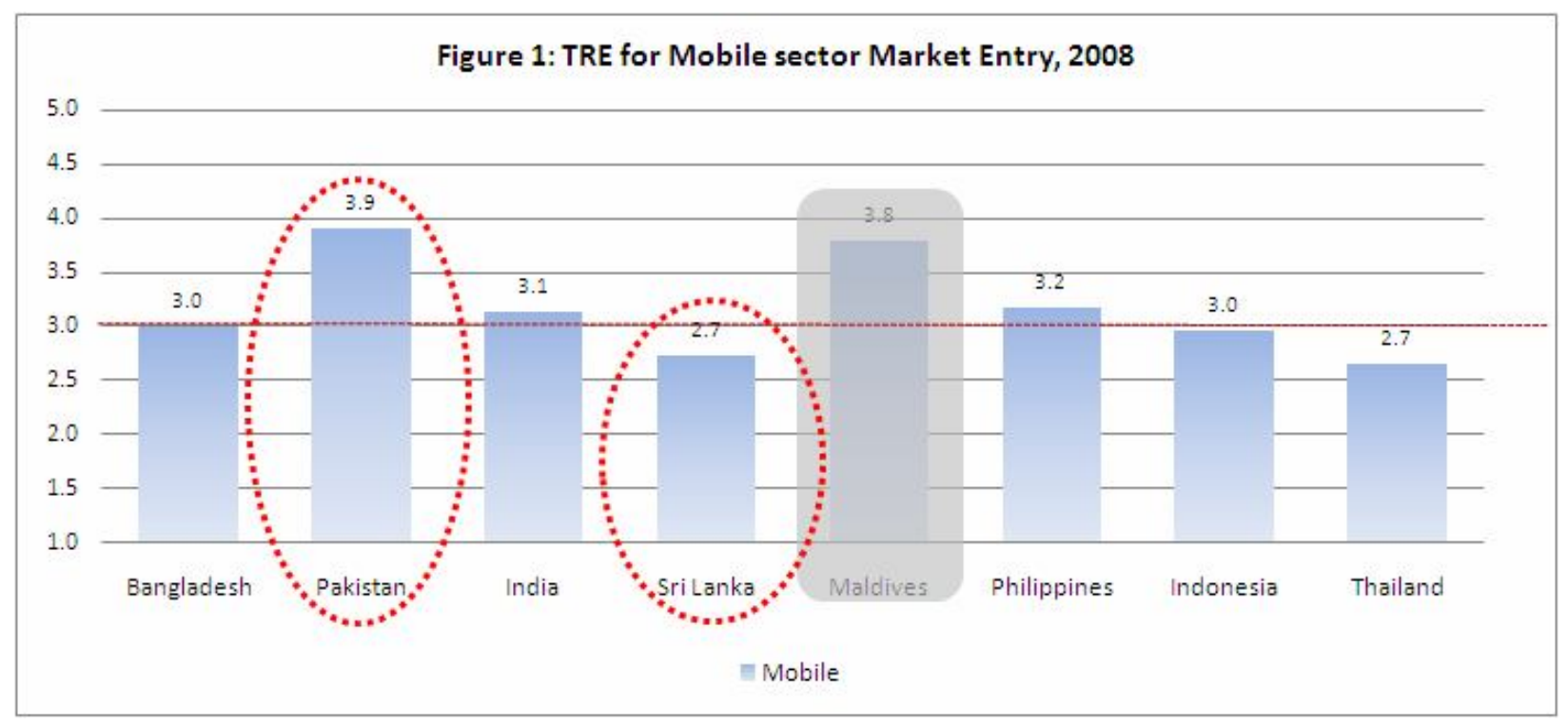

Excluding M aldives (for reasons given above), the clear winner is Pakistan, getting a high TRE of 3.9 for Market Entry (Figure 1). Indeed Pakistan has one of the fastest growing mobile industries in the world (estimated to be the $3^{\text {rd }}$ fastest growing, behind India), with 58.9 access paths per 100 people (compared to 26.22 in India; but with some downward corrections needed for inactive SIM s). Growth has been driven by investments, primarily very large foreign direct investments. Wilson (2008) identifies several factors that contribute to making Pakistan's telecom attractive to investors.

- The conditions for obtaining a new mobile license or renewing and exiting one are straightforward - each operator has to pay USD 291 million. Though this fee is high, once it was announced, it has eliminated discretion on the part of the regulator and therefore nearly eliminates regulatory risk - as long as an operator can pay the fee, access to the market (in the form of a new license or a renewal of existing/ expiring one) is guaranteed.

- The unbundled licensing regime for fixed services has encouraged investors to enter the market and offer services in the area of their choice.

- There are no limitations on foreign ownership of telecom companies and no restrictions on merger and acquisition activity.

- Mobile number portability was implemented in 2007, thereby enabling increased competition amongst players, and giving a reasonable shot at success even for new/smaller players.

The above actions have made Pakistan's telecom sector an attractive destination for regional and international investment. For example, during the time-frame evaluated in this study (2007 -2008), China M obile acquired $100 \%$ of Paktel, Orascom increased its ownership stake in Mobilink to $100 \%$, SingTel purchased $30 \%$ Warid Telecom and OmanTel purchased $60 \%$ of World Call. The total paid by the acquiring companies in the above deals was over USD 1.5 billion. All firms have already started making significant investments in new infrastructure or upgrades. As a result, during 2007-2008 Pakistan's telecom sector attracted over USD 1.4 billion in investments that amounted to around $27 \%$ of total FDI into the country. 
Sri Lanka and Thailand receive the lowest TRE score for M arket Entry in the mobile sector. Sri Lanka's low score can be explained by the non-transparent nature of the licensing process used in the most recent license. Bharti Airtel was awarded a new license in April 2007. No auction mechanism was used and the criteria for selection were never explicitly stated. Furthermore, after obtaining the license, it was a good 21 months before Airtel was able to become operational due to setbacks and delays related to rights of way, interconnection and a host of other issues. At the time the TRE survey was carried out in Sri Lanka, most stakeholders (and even the general public) were expressing concern over the difficulties Airtel was having in starting its operations.

Thailand too suffers from less-than ideal market entry conditions in the mobile sector, giving it one of the lowest scores in the region. There are 3 private concessionaires operating in the Thai mobile sector. But this number is low, given the total size of the market, and the level of competition as measured by $\mathrm{HHI}$ is well above 3,500 , indicating a low level of competition. No new mobile licenses have been issued since the original three concessions were granted. Furthermore, political wrangling and related legal problems have prevented (or at least significantly delayed) the roll out of $3 \mathrm{G}$ services.

\subsubsection{Allocation of Scarce Resources}

Though scarce resources were defined as spectrum, rights of way and numbering, it is likely that spectrum is foremost in the minds of stakeholders. After all, subscriber growth in all three sub-sectors (fixed, mobile and broadband) in all the countries has been driven by wireless technologies, making spectrum a valuable and often scarce resource.

Once again, Pakistan was the top performer, receiving the highest scores in all three sub-sectors. Pakistan in fact is the only country that receives above average (i.e. above 3.0) scores. The 1996 Telecom Act requires the regulator (the Pakistan Telecom Authority) to "receive and expeditiously dispose of applications for the use of radio-frequency spectrum". The Frequency Allocation Board is required to process applications for spectrum within 30 days, by law. In addition, real-time frequency monitoring takes place, ensuring that license conditions are enforced. Finally, in April 2008 Pakistan changed the numbering scheme for telephones from 7 digits to 8 digits, thereby lowering the scarcity of this resource. 


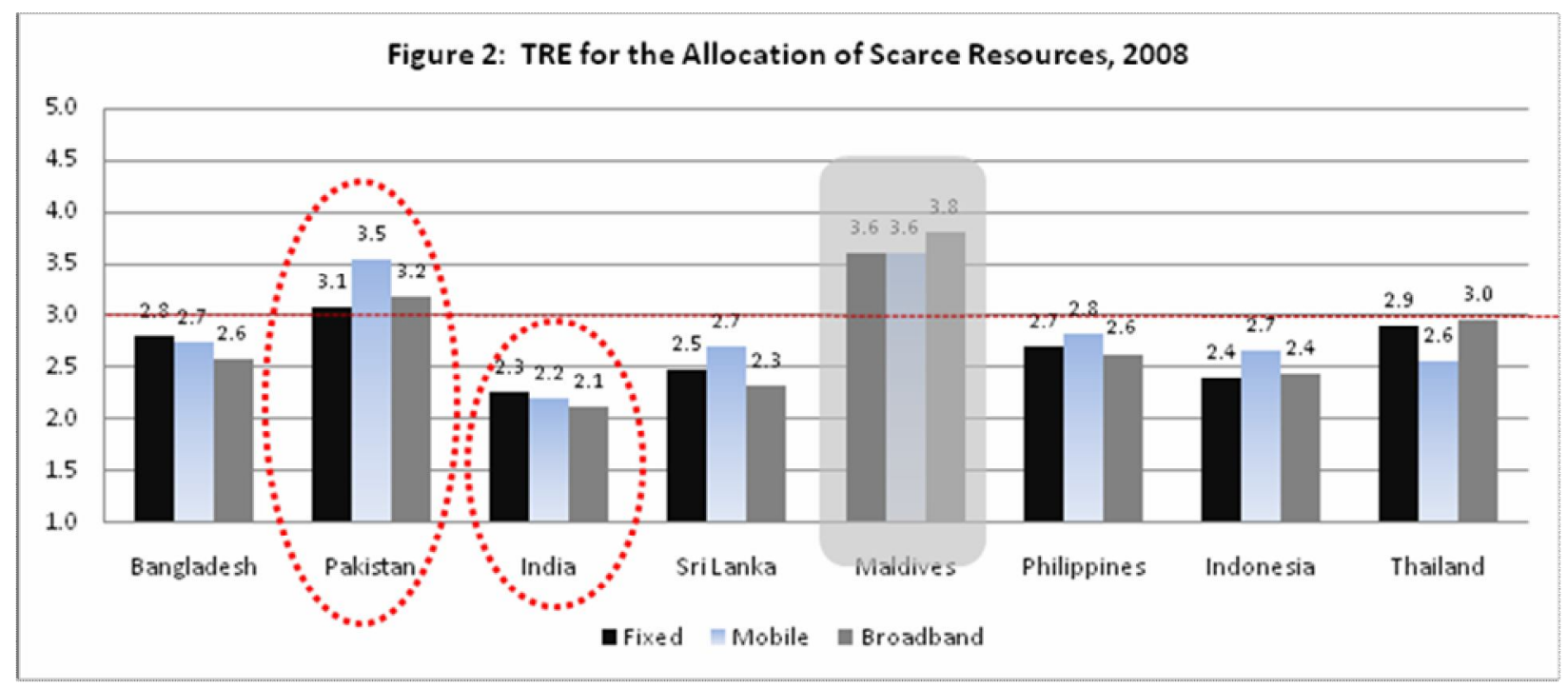

In contrast to Pakistan, India receives the lowest scores in this dimension in all three sub-sectors. India was the lowest performer in the previous (2006) TRE survey also. In fact India's latest TRE scores for this dimension have even marginally decreased since 2006. At a fundamental level, this is due to the purely administrative (as opposed to economic) allocation of spectrum that is practiced in India. Repeated recommendations to auction spectrum have gone unheeded. The amount of spectrum allocated to each operator is linked to the subscriber numbers, not usage. Even here, the regulator (Telecom Regulatory Authority of India) and the policy maker (Department of Telecommunications, DoT) were in disagreement for most of the 2007-2008 year on what the appropriate subscriber-linked formula should be. There is no policy for allocating spectrum beyond the $10 \mathrm{M} \mathrm{Hz}$ that is already allocated, even though most GSM operators have loaded their spectrum well beyond benchmark levels and the CDM A operators are close to reaching that point. The average frequency allotted to an Indian mobile operator is $6.2 \mathrm{M} \mathrm{Hz}$, compared to the world average of $17.18 \mathrm{M} \mathrm{Hz}$. Even if further allocation is agreed upon, there is no spectrum free to allocate: government and defense users are currently occupying valuable bands, making re-farming difficult (M alik, 2008). In addition to all of the above, before and during the time the TRE survey was being carried out in 2008, India's telecom space was abuzz with the controversies related to $2 \mathrm{G}$ and $3 \mathrm{G}$ spectrum allocation. Accusations by various parties about undue advantage or preference being given to the other, and the DoT ruling out auction mechanisms for the allocation of $2 \mathrm{G}$ and other related issues were being publicly and widely debated. Given all this, India's low score in this dimension is not surprising.

\subsubsection{Interconnection}

TRE for Interconnection assesses aspects related to interconnection rates, mechanism for setting those rates, interconnection locations, time taken to obtain interconnection, mechanisms for sharing of related revenue and related costs. 


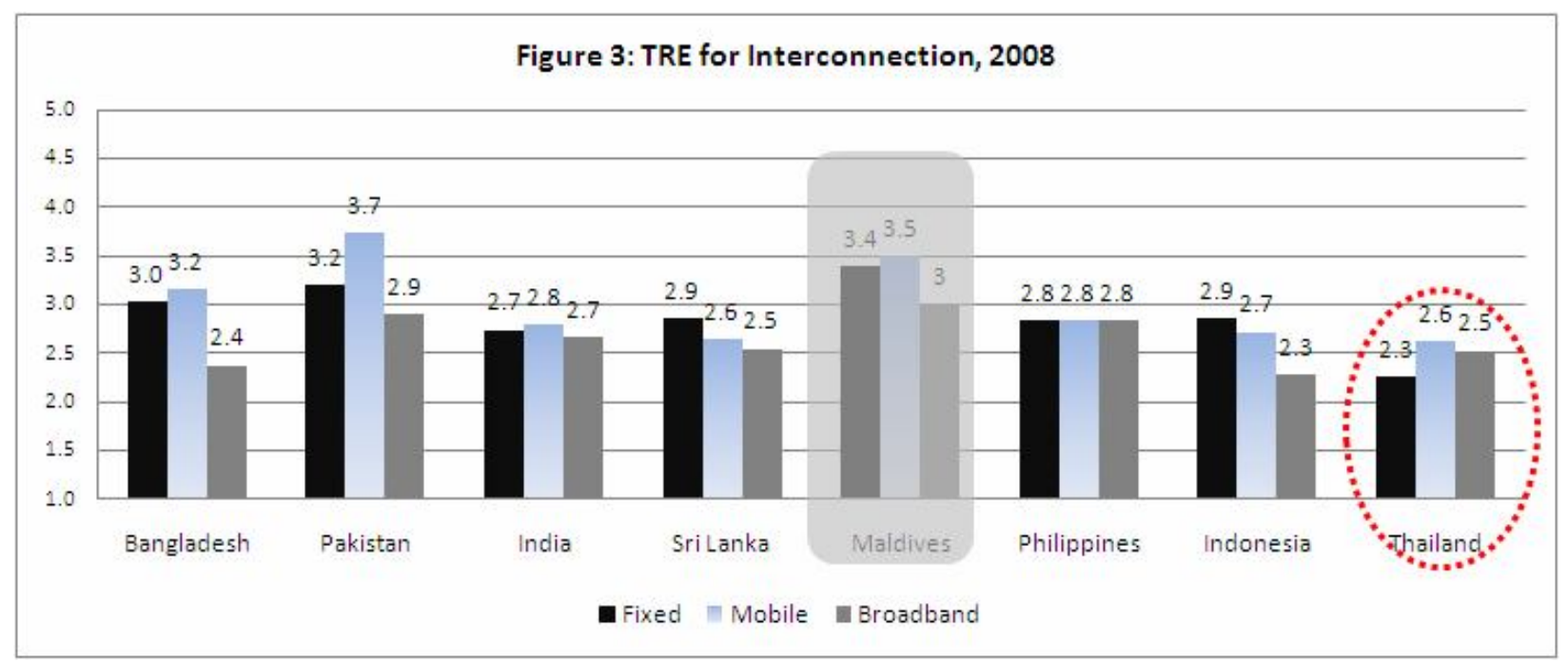

Pakistan is the best performer. The rules in Pakistan mandate each operator to negotiate and interconnection with another operator who makes such a requests. And in practice, operators indeed negotiate their interconnection rates mutually. However the players with significant market power (SMP) are then required to produce/ publish a Reference Interconnection Offer (RIO) detailing the terms they offered to other players. SMP is defined as any operator who has more than $25 \%$ of the revenues in a specified market. Of the countries in the study, Pakistan is one of the few countries that mandate RIOs to be published on a regular basis (though others such as the Maldives published RIOs once when new operators entered the market). Pakistan's TRE score for Interconnection has increased by nearly a point since the 2006 TRE study (for the mobile sector it was 2.8, compared to 3.7 now). This could be due to the increased efficiency with which interconnection disputes are mediated and resolved by the regulator.

In contrast Thailand performs poorly in all 3 sectors. The reasons are to be found in the conflicting rules and regulations, the lack of clear authority on the part of the regulator and the discriminatory nature of interconnection rules. The Thai Business Act (TBA) states the interconnection is mandatory, that interconnection charges be negotiated privately and that the interconnection terms should be nondiscriminatory, and fair. TBA even sets out procedures for dispute resolution and mandates decisions to be given within 30 days. All this is for naught however, because all concession agreements are exempt from such rules. And all private mobile networks operate under concession agreements with the two state enterprises TOT and the CAT, and are legally owned by these two entities. Since private operators are mere concessionaires, all interconnection charges must be negotiated and paid by the two legal license holders only. The terms imposed on the concessionaires are onerous and discriminatory - for example the concession mandates that all private concessionaires of CAT (namely DTAC and True M ove) pay TOT a hefty flat fee of 200 baht (about USD 5.8) per month for each post-paid subscriber and $18 \%$ of revenue for each pre-paid subscriber, while TOT's own concessionaires do not have to pay such a fee. In protest, the two mobile operators had stopped paying interconnection charges to TOT since 2006, and in 2007 the three private concessionaires agreed to interconnect amongst themselves. TOT has filed a 
law suit against at least one of the private operators as a result (Nikomborirak \&Cheevasittiyanon, 2008).

\subsubsection{Tariff Regulation}

This dimension evaluates the regulatory environment related to consumer price regulation.

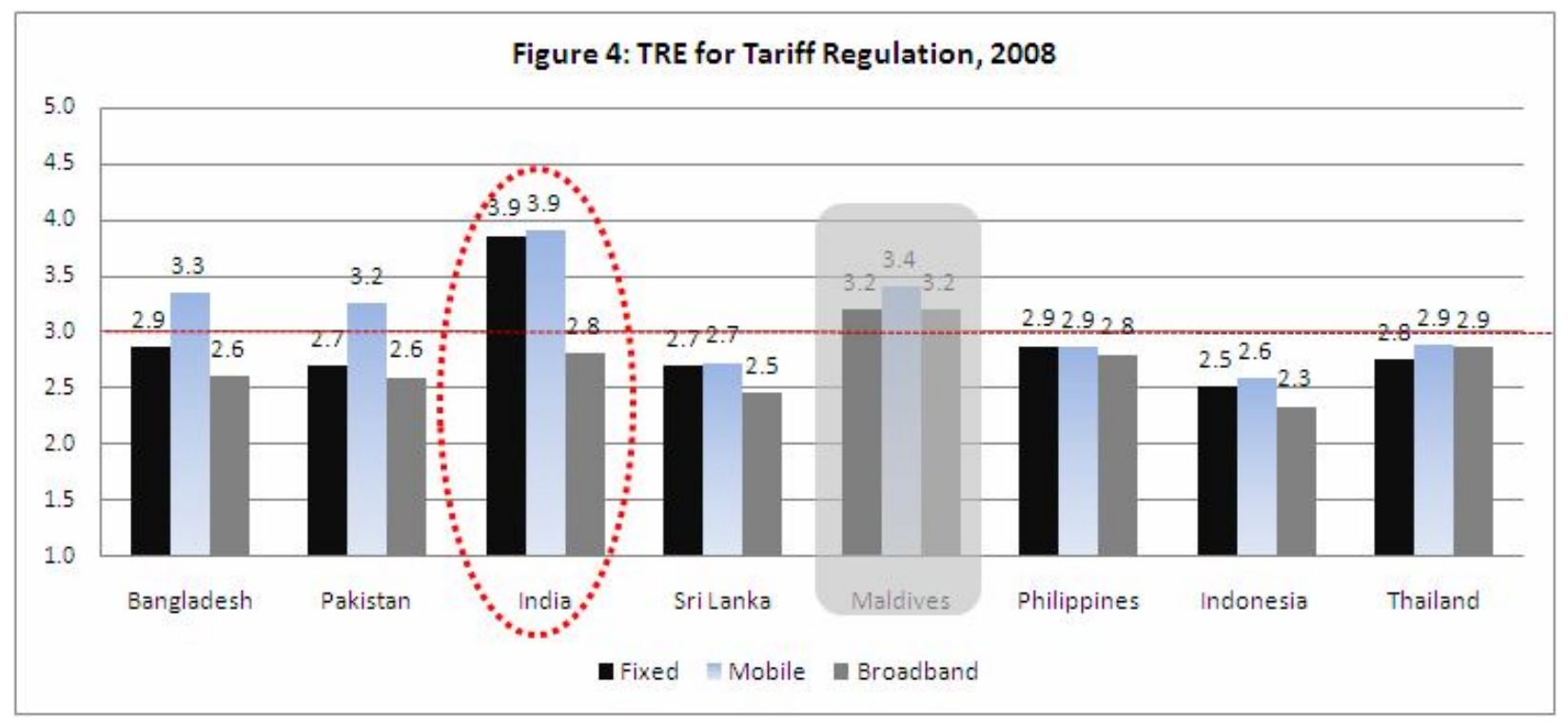

In both fixed and mobile sectors, India is the clear leader. In the 2006 survey too India was heads and shoulders above others. India's TRE scores for Tariff Regulation have even improved since 2006 (fixed has increased from 3.7 to 3.9; mobile has increased from 3.5 to 3.9). In 2002, TRAI stated that emerging market forces could effectively regulate mobile tariffs and that the regulator could therefore step aside. Since then, TRAI has practiced forbearance in regulating most tariffs. Only integrated operators are required to seek prior approval for their tariffs. Despite early opposition from the policy maker and the government, the regulator has proved that its approach was right - with increased competition, Indian consumers today enjoy some of the cheapest tariffs in the world (Nokia 2008 and 2009). In the survey, the stakeholders reward the regulators approach by giving it high scores. In recent times, regulations to slash roaming rates have been enacted.

\subsection{Changes in regulatory practice over time reflected in TRE scores}

In the 2006 TRE survey, among all the countries, India received the lowest scores in the Universal Service dimension (Figure 6). Universal Service was also the lowest scoring among the dimensions within India itself (Figure 7). 


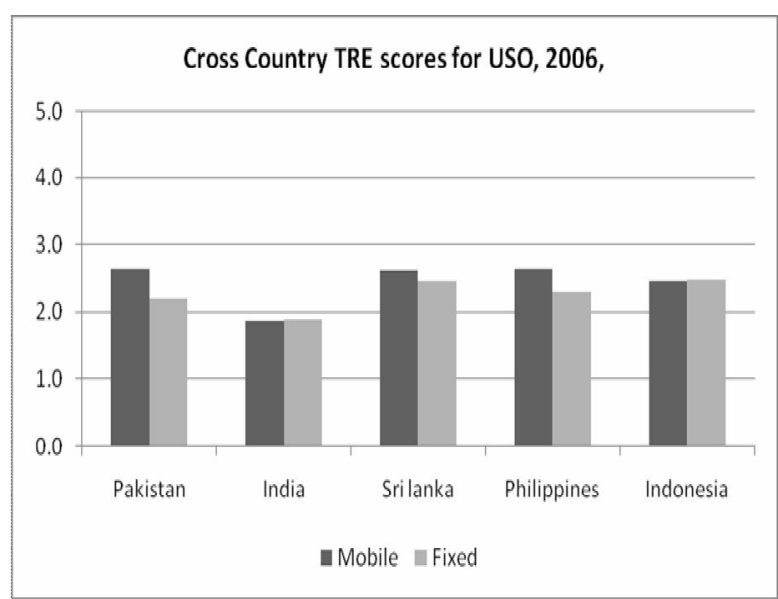

Figure 6

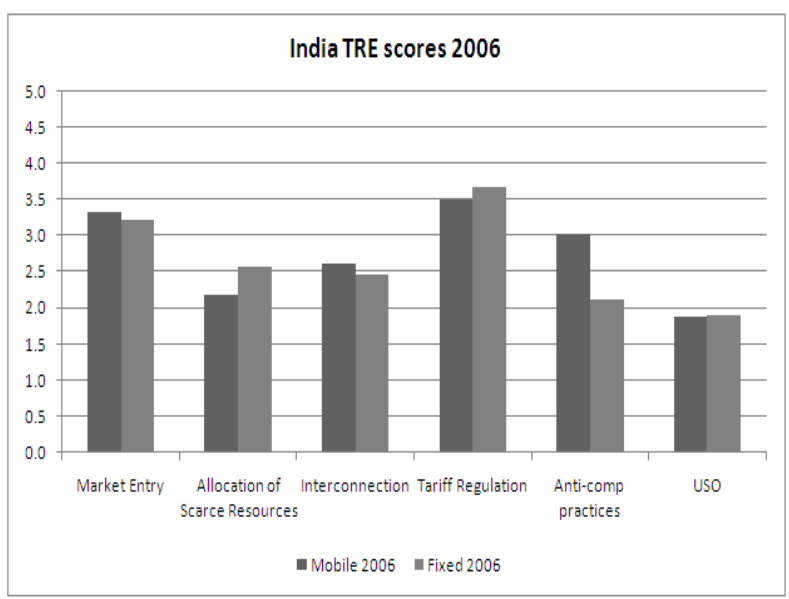

Figure 7

India's low performance in USO (within the country and in comparison to other countries) is attributable to its universal service fund. Until M arch 2007, only fixed line operators could qualify to receive funds from the universal service funds, even though mobile operators were being charged $5 \%$ of their gross revenue as a contribution to the fund. The terms of the fund disbursement was such that only the incumbent would qualify to receive funds in each round of disbursement. The result was, in essence, a subsidy to the incumbent fixed operator by the mobile industry. Yet, mobile was driving nearly all of the rural growth in access lines in India (Figure 8). So the low TRE scores was no surprise. In addition to this, at the time, India had the world's second largest universal service fund with over USD 4 billion collected yet undisbursed (Malik 2007, Malik 2008).

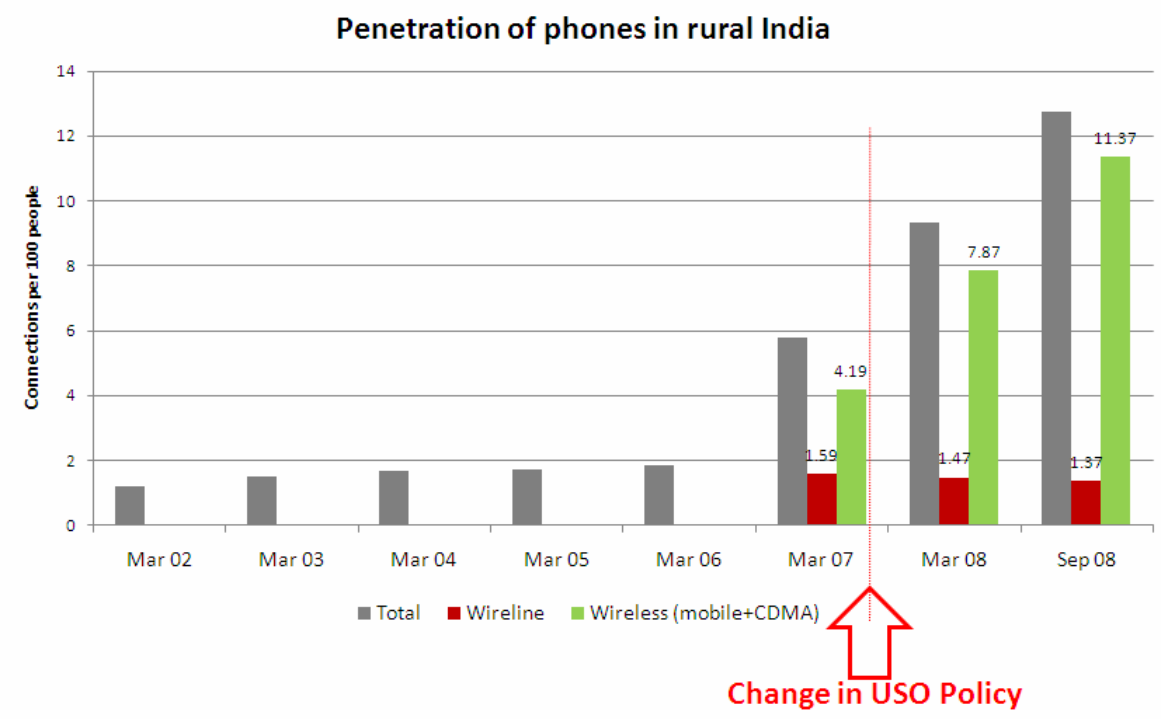

Figure 8. Author, based on data from the Telecom Regulatory Authority of India

In March 2007, the certain sections of the universal service policy were finally changed, enabling mobile operators to bid for last-mile connectivity funds. In theory (to an outsider) this is a positive move by the 
regulator and the policy maker. If the TRE reflects the reality of stakeholders, the TRE scores should also show an improved (positive perception) after the policy change. Indeed this is the case - the 2008 TRE survey in India (conducted 14 or so months after the USO policy changed) show increased scores in the USO dimension (Figure 9). The mobile score increases by $64 \%$. This is the biggest increase in TRE scores seen yet, for any dimension in any country.

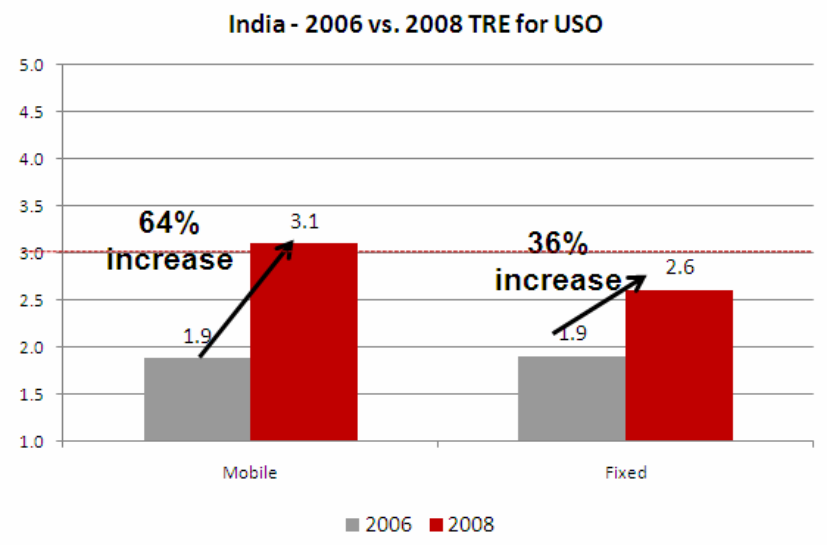

Figure 9

While things have improved, India still accounts for nearly $50 \%$ of the undisbursed universal service funds in the world. Operators are still charged $3 \%$ of gross revenues towards the USO fund. While TRE scores improved hugely when compared to 2006, we see this less-than-perfect situation reflected in the fact that the average (of fixed, mobile and broadband) TRE score for USO in India is still only 2.6, well below the 3.0 point of average performance

\subsection{Discussion of methodology and future research}

In implementing the TRE survey in three cycles since 2005, the methodology has evolved gradually. The 2005 pilot only contained five dimensions. In 2006 it was increased to six, and in 2008 to seven. While increasing the dimensions allows for finer analysis of the regulatory environments, it has several negatives. First, new dimensions that are not taken from the GATS regulatory reference paper may delegitimize the universal applicability of the TRE framework. Second, adding new dimensions increases the length of the questionnaire. While one extra question may not be an issue in most surveys, it might be a problem for the TRE. The target respondents of the TRE survey (CEOs of companies, for example) are persons whose time and attention is extremely difficult to command, even for the 7 minutes it takes to complete the survey on average. A questionnaire that is too long risks being thrown away, or being assigned to a junior person to fill. Therefore shorter questionnaires are preferred. Yet in 2008, the research team added 7 extra questions, by introducing a new subsector (broadband) in addition to the two that existed before (fixed and mobile).

The evaluation of subsectors separately, specially the evaluation of fixed and mobile sub-sectors separately, has also been debated for reasons unrelated to increasing length of the questionnaire. 
Fixed-mobile convergence is increasingly making it meaningless to separately view the two sectors. Further, in nearly all the countries surveyed, fixed line growth is stagnant or negative, while mobile phones and SIM growth is exploding. For consumers the fixed sectors appears to be of low importance. Some operators too have refused to complete the fixed sector questions in the TRE survey. And most countries have one or two fixed operators only. As a result, respondents in Category 1 are mostly from mobile companies. All these reasons point towards merging the two sectors and evaluating them as one (or eliminating the fixed sector). Yet, regulation of fixed sectors still remains different to the regulation of the mobile sector in several countries. Therefore analyzing them separately may be quite important. A decision will be taken in the near future, taking these issues into consideration.

Using a survey as a research tool carries some inherent methodological problems. Perception bias is one. Certain biases can be controlled for - for example, balanced representation by stakeholders who are likely to have opposing incentive structures is ensured through the assignment of weights. It is possible that homogenous groups (e.g. all respondents from a particular country) carry other types of biases. For example, cultural factors in a particular country may create a tendency to exaggerate, or a tendency to not be completely forthcoming. Analyzing dimensions within such country is still possible, even if such biases exist (since the bias carries through to all scores across all dimensions). But caution is needed if that country is compared to another country, one whose stakeholders have a different bias.

Finally, in an ideal survey, internal consistency (does a respondent evaluate similar questions in a similar manner) can and should be checked. Yet the TRE questionnaire must be kept short, in order to ensure senior stakeholders respond. Therefore it is not possible to design (a longer) question that tests for internal consistency. 


\subsection{Conclusions}

The paper presents a method to capture stakeholder perceptions about the dimensions of the telecom regulatory and policy environment in a country.

The results, once analyzed in the context of each country, can identify best practices and worst practices. Within one country, the results are useful for diagnosing the finer problems of the regulatory system. The results are also useful to track the evolution of regulation over time. Because it is a measure of perception, regulators may use the results understand how their actions (or inaction) is perceived by stakeholders.

Future work points towards testing the TRE scores against sector performance. For example, do higher TRE scores necessarily result in increased connectivity, increased choice etc, after controlling for other factors (such as the political climate, economic conditions)? Goswami \& Malik (2007) analyze the 2006 TRE results and sector performance for Indonesia and India and show that despite good TRE scores relative to Indonesia, a key component of India's sector performance as measured by mobile and fixed lines per 100 people lags behind significantly. However, they conclude that Indonesia's good performance (in spite of the poorer regulatory environment, as indicated by TRE scores) is likely to be the exception rather than the rule. Further work needs to be done on the correlation of TRE scores to performance. But such work has to be done keeping in mind that there will nearly always be a lag between regulatory action and final sector performance. As the ITU (2007) states, referring to the 2006 TRE results, "Their evaluation of the regulatory environment is in general agreement with sector performance, as measured by the DOI [Digital Opportunity Index]. However, the fit is not perfect: for instance, Sri Lanka actually gained two places in the DOI, but it lagged behind, ranked fourth out of the six countries in regulatory performance. This suggests lags in relating changes in the regulatory environment to sector performance". 


\subsection{References}

Alampay, E. A, (2008), Telecom Regulatory Environment in the Philippines: Results and Analysis of the 2008 TRE Survey. http://lirneasia.net/projects/2008-2010/indicators-continued/telecom-regulatoryenvironment/

Berg, S., (2000), Sustainable Regulatory Systems: Laws, Resources, and Values, Utilities Policy, Vol. 9, No. 4, 159-70.

Berg, S. (2009), Characterizing the Efficiency and Effectiveness of Regulatory Institutions, Public Utility Research Center, University of Florida.

http://www.cba.ufl.edu/purc/purcdocs/papers/0909_Berg_Characterizing the Effciency.pdf

Brown, A., Stern, J., Tenenbaum B., (2006), Handbook for Evaluating Infrastructure Regulatory Systems, The World Bank, Washington DC

Edwards, G. and L. Waverman (2006), The Effects of Public Ownership and Independence on Regulatory Outcomes - a study of interconnect rates in EU telecommunications. Journal of Regulatory Economics, 29:1

Fink, C., A. M attoo, and R. Rathindran (2002), An Assessment of Telecommunications Reform in Developing Countries, Policy Research Working Paper 2909. World Bank, Washington D. C.

Galpaya, H. (2008), Telecom Regulatory Environment in the Maldives: Results and Analysis of the 2008 TRE Survey. http://lirneasia.net/projects/2008-2010/indicators-continued/telecom-regulatoryenvironment/

Goswami D. and M alik P. (2007), Telecom growth in poor regulatory environments: a comparative analysis of Indonesia and India, paper presented at the International Association for M edia and Communication Research (IAM CR) conference, Paris, July 2007

ITU (2007). World Information Society Report 2007: Beyond W SIS, International Telecommunications Union, Geneva, 2007. http:// www.itu.int/osg/spu/publications/worldinformationsociety/2007/

Kessides, I. N. (2004), Reforming Infrastructure: Privatization, Regulation, and Competition, World Bank and Oxford University Press

Khaled, M. (2008), Telecom Regulatory Environment in Bangladesh: Results and Analysis of the 2008 TRE Survey. http://lirneasia.net/projects/2008-2010/indicators-continued/telecom-regulatory-environment/

Knight-J ohn, M., (2008), Telecom Regulatory Environment in Sri Lanka: Results and Analysis of the 2008 TRE Survey. http://lirneasia.net/projects/2008-2010/indicators-continued/telecom-regulatoryenvironment/ 
Levy, B., Spiller, P.T. (1994), The Institutional Foundations of Regulatory Commitment: A Comparative Analysis of Telecommunications Regulation. Journal of Law, Economics, \& Organization, Vol. 10, No. 2, pp. 201-246, Oxford University Press

Malik, P., (2007). Universal Service Obligations: To Incumbents, in ICT Infrastructure in Emerging Asia: Policy and Regulatory Roadblocks, eds. R. Samarajiva \& A. Zainudeen. New Delhi: Sage India

Malik P. (2008), Telecom Regulatory Environment in India: Results and Analysis of the 2008 TRE Survey. http://lirneasia.net/projects/2008-2010/indicators-continued/telecom-regulatory-environment/

NERA (1998). National Economic Research Associates, Governance and Regulatory Regimes for Private Sector Infrastructure Development, ADB RETA 5758-REG, http://www.adb.org/Documents/Reports/Consultant/31610-REG/default.asp, last visited 5 M ay 2009

Nikomborirak, D., Cheevasittiyanon, S., (2008), Telecom Regulatory Environment in Thailand: Results and Analysis of the 2008 TRE Survey. http://lirneasia.net/projects/2008-2010/indicatorscontinued/telecom-regulatory-environment/

Noll, Roger, (2000). Telecommunications Reform in Developing Countries." In SIEPR Policy Paper, Stanford, 2000

Nokia (2008). Affordability key in bring digital inclusion. In Expanding Horizons (Quarter 12008$)$ : 12-13. http://www.nokiasiemensnetworks.com/NR/rdonlyres/53DB19A3-36A8-4AE5-B1AD-

F53A26AE88FA/0/NokiaExpandingHorizons012008.pdf

Nokia (2009). Affordability key in bringing digital inclusion. Expanding Horizons (Quarter 1 2009): 10-12. http://expandinghorizons.nokia.com/issues/?issue=ExpandingHorizonsQ12009

Prayas Energy Group (2003), A Good Beginning But Challenges Galore: A Survey Based Study on Resources, Transparency, and Public Participation in Electricity Regulatory Commissions in India, February 2003, Pune

Samarajiva, R. \& A. Dokeniya (2003, M arch) Regulation and Investment: Sri Lanka Case Study, World Dialogue on Regulation Discussion Paper 0303b. http://www.regulateonline.org/content/view/207/31/

Samarajiva, R. \& A. Dokeniya with Sabina Fernando, Shan M anikkalingam \& Amal Sanderatne (2005), Regulation and investment: Sri Lanka case study, in Stimulating investment in network development: Roles for regulators, eds. A.K M ahan and W.H. Melody, pp. 141-76. Monte Video: World Dialog on Regulation

Samarajiva R., Galpaya H., Goswami D., Ratnadiwakara D., Telecom Regulatory Environment (TRE) assessment: methodology and implementation results from five emerging economies, paper presented at the $35^{\text {th }}$ Telecommunications Policy Research Conference, Virginia, USA, September 2007. http://web.si.umich.edu/tprc/papers/2007/683/SamarajivaGalpayaRatnadiwakara TPRC.pdf 
Stern, J., Cubbin, J., (2005), Regulatory Effectiveness: The Impact of Regulation and Regulatory Governance Arrangements on Electricity Industry Outcomes, World Bank Policy Research Working Paper 3536, March 2005

Stern, J. \& Holder, S., (1999), Regulatory governance: criteria for assessing the performance of regulatory systems. An application to infrastructure industries in the developing countries of Asia, Utilities Policy, Vol. 8, pp.33-50

Wattegama C., Soehardjo J., Kapugama N., (2008), Telecom Regulatory Environment in Indonesia: Results and Analysis of the 2008 TRE Survey. http://lirneasia.net/projects/2008-2010/indicatorscontinued/telecom-regulatory-environment/

Weeks, M. and Williamson, B. (2006). A sound basis for evidence based policy? A critique of the ECTA regulatory scorecard and SPC Network papers on investment and broadband. A Report for ETNO by Indepen Consulting Ltd, June 2006.

http://www.etno.be/Portals/34/publications/other/Indepen\%20Study June\%202006.pdf

Wilson J. (2008), Telecom Regulatory Environment in Pakistan: Results and Analysis of the 2008 TRE Survey. http://lirneasia.net/projects/2008-2010/indicators-continued/telecom-requlatory-environment/ 


\subsection{Annex 1: TRE survey results (weighted final scores) for 2008}

Scores are presented by country. Total number of respondents in 2008 was 412.

\section{Bangladesh}

\begin{tabular}{lccc}
\hline Dimension & Fixed & Mobile & Broadband \\
\hline Market entry & 3.4 & 3.0 & 2.6 \\
\hline Allocation of scarce resources & 2.8 & 2.7 & 2.6 \\
\hline Interconnection & 3.0 & 3.2 & 2.4 \\
\hline Tariff regulation & 2.9 & 3.3 & 2.6 \\
\hline $\begin{array}{l}\text { Regulation of anti- } \\
\text { competitive practices }\end{array}$ & 2.8 & 2.9 & 2.3 \\
\hline Universal service obligation & 2.2 & 2.3 & 2.0 \\
\hline Quality of Service & 2.5 & 3.1 & 1.9 \\
\hline
\end{tabular}

\section{Indonesia}

\begin{tabular}{lccc}
\hline Dimension & Fixed & Mobile & Broadband \\
\hline Market entry & 2.6 & 3.0 & 2.4 \\
\hline Allocation of scarce resources & 2.4 & 2.7 & 2.4 \\
\hline Interconnection & 2.9 & 2.7 & 2.3 \\
\hline Tariff regulation & 2.5 & 2.6 & 2.3 \\
\hline $\begin{array}{l}\text { Regulation of anti-competitive } \\
\text { practices }\end{array}$ & 2.4 & 2.5 & 2.4 \\
\hline Universal service obligation & 2.1 & 2.1 & 2.2 \\
\hline Quality of Service & 2.5 & 2.3 & 2.3 \\
\hline
\end{tabular}

\section{India}

\begin{tabular}{lccc}
\hline & Fixed & Mobile & Broadband \\
\hline Market entry & 2.7 & 3.1 & 2.8 \\
\hline Allocation of scarce resources & 2.3 & 2.2 & 2.1 \\
\hline Interconnection & 2.7 & 2.8 & 2.7 \\
\hline Tariff regulation & 3.9 & 3.9 & 2.8 \\
\hline $\begin{array}{l}\text { Regulation of anti-competitive } \\
\text { practices }\end{array}$ & 2.3 & 2.7 & 2.4 \\
\hline Universal service obligation & 2.6 & 3.1 & 2.1 \\
\hline Quality of Service & 2.8 & 2.8 & 2.2 \\
\hline
\end{tabular}

\section{Maldives}

\begin{tabular}{lccc}
\hline Dimension & Fixed & Mobile & Broadband \\
\hline Market entry & 2.9 & 3.8 & 3.5 \\
\hline Allocation of scarce resources & 3.6 & 3.6 & 3.8 \\
\hline Interconnection & 3.4 & 3.5 & 3 \\
\hline Tariff regulation & 3.2 & 3.4 & 3.2 \\
\hline
\end{tabular}


Regulation of anti-competitive

\begin{tabular}{llll} 
practices & 2.8 & 3.1 & 2.8 \\
\hline Universal service obligation & 3.6 & 3.5 & 2.9 \\
\hline Quality of Service & 3.6 & 3.8 & 3.5 \\
\hline
\end{tabular}

\section{Pakistan}

\begin{tabular}{lccc}
\hline & Fixed & Mobile & Broadband \\
\hline Market entry & 3.0 & 3.9 & 3.2 \\
\hline Allocation of scarce resources & 3.1 & 3.5 & 3.2 \\
\hline Interconnection & 3.2 & 3.7 & 2.9 \\
\hline Tariff regulation & 2.7 & 3.2 & 2.6 \\
\hline $\begin{array}{l}\text { Regulation of anti- } \\
\text { competitive practices }\end{array}$ & 2.4 & 2.8 & 2.5 \\
\hline Universal service obligation & 2.8 & 3.2 & 2.0 \\
\hline Quality of Service & 2.7 & 3.2 & 2.7 \\
\hline
\end{tabular}

Philippines

\begin{tabular}{lccc}
\hline Dimension & Fixed & Mobile & Broadband \\
\hline Market entry & 2.9 & 3.2 & 3.0 \\
\hline Allocation of scarce resources & 2.7 & 2.8 & 2.6 \\
\hline Interconnection & 2.8 & 2.8 & 2.8 \\
\hline Tariff regulation & 2.9 & 2.9 & 2.8 \\
\hline Regulation of anti- & & & \\
competitive practices & 2.7 & 2.5 & 2.6 \\
\hline Universal service obligation & 2.7 & 2.6 & 2.5 \\
\hline Quality of Service & 2.9 & 3.2 & 2.7 \\
\hline
\end{tabular}

\section{Sri Lanka}

\begin{tabular}{lccc}
\hline Dimension & Fixed & Mobile & Broadband \\
\hline M arket entry & 2.7 & 2.7 & 2.4 \\
\hline Allocation of scarce resources & 2.5 & 2.7 & 2.3 \\
\hline Interconnection & 2.9 & 2.6 & 2.5 \\
\hline Tariff regulation & 2.7 & 2.7 & 2.5 \\
\hline $\begin{array}{l}\text { Regulation of anti-competitive } \\
\text { practices }\end{array}$ & 2.6 & 2.7 & 2.6 \\
\hline Universal service obligation & 2.8 & 2.9 & 2.6 \\
\hline Quality of Service & 2.9 & 2.9 & 2.5 \\
\hline
\end{tabular}

\section{Thailand}

\begin{tabular}{lrcc}
\hline Dimension & Fixed & Mobile & Broadband \\
\hline M arket entry & 3.1 & 2.7 & 3.4 \\
\hline Allocation of scarce resources & 2.9 & 2.6 & 3.0 \\
\hline
\end{tabular}




\begin{tabular}{llll} 
Interconnection & 2.3 & 2.6 & 2.5 \\
\hline Tariff regulation & 2.8 & 2.9 & 2.9 \\
\hline $\begin{array}{l}\text { Regulation of anti- } \\
\text { competitive practices }\end{array}$ & 2.6 & 2.6 & 2.8 \\
\hline Universal service obligation & 2.6 & 2.5 & 2.4 \\
\hline Quality of Service & 2.9 & 3.0 & 2.8 \\
\hline
\end{tabular}




\subsection{Annex 2: Samples of documents from the TRE survey}

\subsection{Questionnaire}

Questionnaire Number :

\section{Telecom Regulatory Environment for <Country>}

You are kindly requested to make your frank assessments of the telecom regulatory environment (TRE) for the year 12 months ending <Month, Year> for the fixed, mobile and broadband telecom sectors on a five-point scale.

The dimensions used in this questionnaire are broadly based on the Reference Paper of the Fourth Protocol of the General Agreement on Trade in Services and are briefly described below. A fact-sheet of key events in the Telecom Regulatory Environment is also attached for your reference for the period $<$ start month $>-<$ end month $><$ year $>$.

Completing the Questionnaire should take 5-7 minutes of your time. Please email the completed questionnaire to <email address $>$ or fax it to $<$ fax number $>$. If you prefer, you can complete the same survey online by simply going to $<\mathrm{URL}$, unique $>$.

Please find a below a table defining the Dimensions covered in the survey for your reference while completing the survey to follow.

\begin{tabular}{|c|c|}
\hline Dimension & Aspects Covered \\
\hline Market Entry & $\begin{array}{l}\text { Transparency of licensing. Applicants should know the terms, conditions, criteria } \\
\text { and length of time needed to reach a decision on their application. License } \\
\text { conditions. Exclusivity issues. }\end{array}$ \\
\hline Scarce Resources & $\begin{array}{l}\text { Timely, transparent and non-discriminatory access to spectrum allocation. } \\
\text { Numbering and rights of way: frequency allocation, telephone number allocation, } \\
\text { tower location rights. }\end{array}$ \\
\hline Interconnection & $\begin{array}{l}\text { Interconnection with a major operator should be ensured at any technically } \\
\text { feasible point in the network. Quality of interconnection comparable to similar } \\
\text { services offered by own network. Reasonable rates for interconnection. } \\
\text { Unbundling of interconnection. Interconnection offered without delay. Sharing of } \\
\text { incoming and outgoing IDD revenue. Payment for cost of interconnection links and } \\
\text { switch interface. Payment for cost of technical disruption of interconnection. }\end{array}$ \\
\hline Tariff Regulation & Regulation of tariffs charged from consumers. \\
\hline $\begin{array}{l}\text { Regulation of Anti } \\
\text { Competitive } \\
\text { Practices }\end{array}$ & $\begin{array}{l}\text { Anti-competitive cross subsidisation. Using information obtained from competitors } \\
\text { with anti-competitive results. Not making technical information about essential } \\
\text { facilities and commercially relevant information available to competitors on a } \\
\text { timely basis. Excessive prices. Price discrimination and predatory low pricing. } \\
\text { Refusal to deal with operators and other parties. Vertical restraints. Technical } \\
\text { disruption of interconnection. Sharing of towers and facilities by parent company } \\
\text { and subsidiaries in different segments of the market. }\end{array}$ \\
\hline $\begin{array}{l}\text { Universal Service } \\
\text { Obligation (USO) }\end{array}$ & $\begin{array}{l}\text { Administration of the universal service program/fund in a transparent, non- } \\
\text { discriminatory and competitively neutral manner and is not more burdensome than } \\
\text { necessary for the kind of universal service defined by the policymakers. }\end{array}$ \\
\hline $\begin{array}{l}\text { Quality of Service } \\
\text { (QoS) }\end{array}$ & $\begin{array}{l}\text { The actual performance of a service with respect to what is promised, depending } \\
\text { upon the network traffic control mechanisms. Specific criteria may be call quality } \\
\text { (for mobile and fixed), connection speeds or throughput (for broadband) }\end{array}$ \\
\hline
\end{tabular}




\subsection{Questionnaire}

Below is the sample questionnaire for the fixed sector. Similar pages are attached for the other 2 sectors (mobile and broadband). Only the title of the page is changed to represent the sector

\section{MOBILE SECTOR Telecom Requlatory Environment, for start-month, Year- <end-month,} Year>

Please TICK the number that best represents the quality of the regulatory environment for each dimension. The lower number represents Highly Ineffective and the higher number represents Highly Effective. If you feel you do not have sufficient information about a particular question, you may choose to leave it blank.

M 1

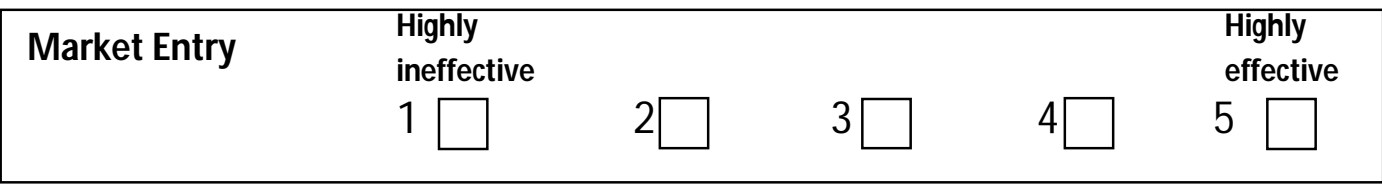

M2

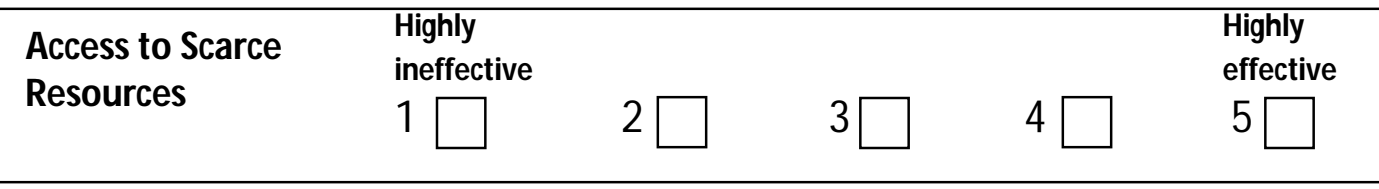

M 3

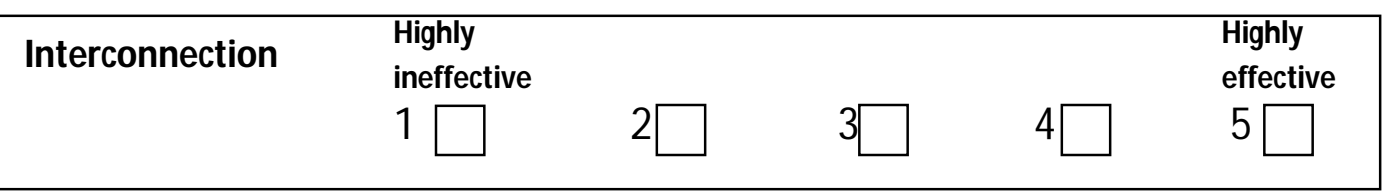

M4

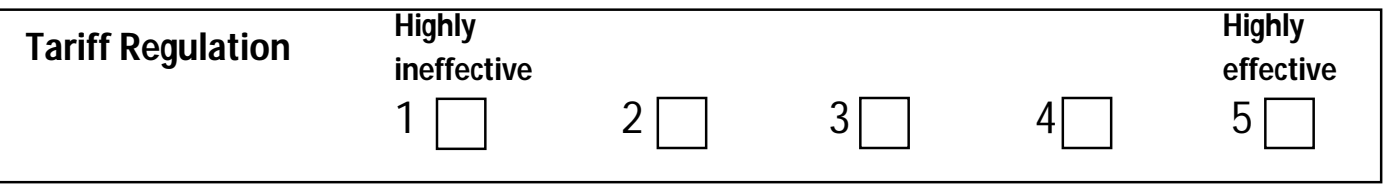

M5

\begin{tabular}{|c|c|c|c|c|c|}
\hline $\begin{array}{l}\text { Regulation of } \\
\text { Anti-competitive }\end{array}$ & $\begin{array}{l}\text { Highly } \\
\text { ineffective } \\
1\end{array}$ & & & & $\begin{array}{l}\text { Highly } \\
\text { effective } \\
5 \square\end{array}$ \\
\hline Practices & $1 \square$ & $2 \square$ & $3 \square$ & $4 \square$ & $5 \square$ \\
\hline
\end{tabular}

M6

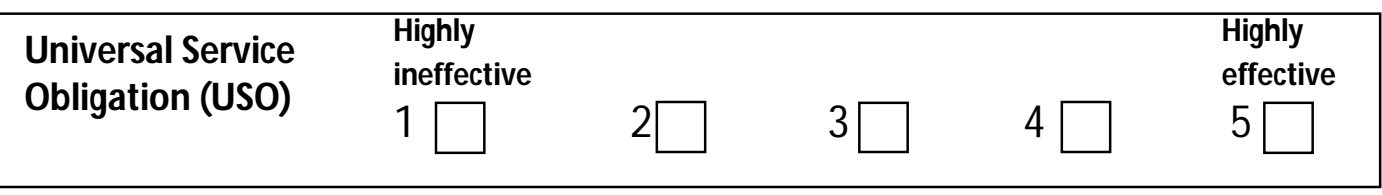

M 7

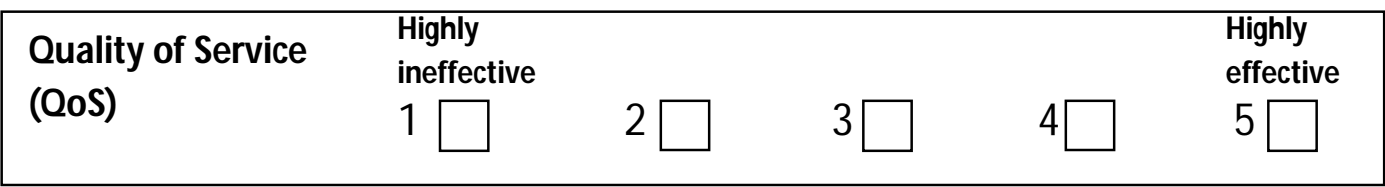




\section{Comments:}

\subsection{Summary of Recent Regulatory and Policy Events}

The following is the document used in India in the 2006 survey. It covers the significant events for the 12 months preceding the survey.

Key Regulatory Events for India; June 2005-June 2006

\begin{tabular}{|c|c|}
\hline Date & Subject \\
\hline \multicolumn{2}{|l|}{2006} \\
\hline 27 June & Study Paper on Financial analysis of Telecom Industry of China and India. \\
\hline 16 June & $\begin{array}{l}\text { Consultation Paper On Admissibility of Revenue Share between Visiting Network and } \\
\text { Terminating Network for Roaming Calls. The key issue in this paper is that in case of } \\
\text { roaming, whether the terminating network service provider should get only the prescribed } \\
\text { termination charges or in view of higher roaming charges, should there be any revenue } \\
\text { share arrangement between the visiting network service provider and the terminating } \\
\text { network service provider. }\end{array}$ \\
\hline 13 June & $\begin{array}{l}\text { Consultation Paper on Interconnect Usage Charges (IUC) for Short Message Service } \\
\text { (SMS). This consultation paper mainly discusses the need for regulatory intervention for } \\
\text { Interconnect usage charges, specifically for SMS carriage and termination charges. }\end{array}$ \\
\hline 12 June & $\begin{array}{l}\text { Consultation paper on Allocation and pricing of spectrum for } 3 G \text { services and Broadband } \\
\text { Wireless Access. This paper discusses } 3 G \text { spectrum allocation and pricing related issues, } \\
\text { issues related to spectrum for Broadband Wireless Access. These technologies hold great } \\
\text { potential for the rapid and comparatively inexpensive deployment of broadband services } \\
\text { especially in rural India. }\end{array}$ \\
\hline 6 June & $\begin{array}{l}\text { Proposed amendments in the Cable Television Networks (Regulation) Act, } 1995 \text { and the } \\
\text { existing Telecom Licenses for facilitation of growth of IPTV services }\end{array}$ \\
\hline 24 May & $\begin{array}{l}\text { Consultation Paper on Fixing the Benchmarks pertaining to Quality of Service for } \\
\text { Broadband. This paper discusses the various issues relating to Broadband Quality of } \\
\text { Service parameters, the international practices, various broadband access technologies } \\
\text { and also suggests various Quality of Service parameters for Broadband and their } \\
\text { benchmarks. }\end{array}$ \\
\hline 21 April & Consultation Paper on Issues relating to Commercial Tariff. \\
\hline 21 March & The Telecommunication Tariff (Forty third Amendment) Order 2006 (3 of 2006). \\
\hline
\end{tabular}




\begin{tabular}{|c|c|}
\hline 21 March & $\begin{array}{l}\text { gulation on Code of Practice for Metering and Billing Accuracy. } \\
\text { tp://www.trai.gov.in/trai/upload/Regulations/44/regu21mar06.pdf }\end{array}$ \\
\hline 20 March & TRAI releases Recommendations on Next Generation Networks (NGN) \\
\hline 10 March & $\begin{array}{l}\text { The Telecommunication Interconnection Usage Charges (Seventh Amendment) } \\
\text { Regulation ( } 2 \text { of 2006) } \\
\text { In Schedule III of The Telecommunication Interconnection Usage Charges Regulation, } \\
2003 \text { (4 of 2003), the following entries shall substitute the existing entries relating to } \\
\text { paragraph 3.2.2:- } \\
\text { 3.2.2 For calculating ADC, Adjusted Gross Revenue shall have the same meaning as } \\
\text { given in the respective licenses; } \\
\text { PROVIDED that in calculating the ADC as a percentage of Adjusted Gross Revenue } \\
\text { (AGR) of a Universal Access Service Licensee/Basic Service Operator, the revenue from } \\
\text { Rural Fixed Wireline subscribers shall be excluded." }\end{array}$ \\
\hline 8 March & $\begin{array}{l}\text { TRAI provides its recommendations on mobile number portability: Mobile Number } \\
\text { Portability implementation process should be initiated in our country. A time frame } \\
\text { of } 12 \text { months between the acceptance of recommendation by the Government } \\
\text { and launch of this facility is recommended. It is recommended that this facility } \\
\text { should be available to mobile subscribers tentatively by } 1 \text { st April } 2007 \text {. }\end{array}$ \\
\hline 7 March & $\begin{array}{l}\text { The Telecommunication (Broadcasting and Cable) Services (Second) Tariff (fourth } \\
\text { Amendment) Order } 2006 \text { ( } 1 \text { of 2006). To give effect to this a Tariff Amendment Order has } \\
\text { been issued in which the words Ordinary Cable Subscriber, Commercial Cable Subscriber } \\
\text { has been defined and the definition of 'charges' has been amended and a new clause to } \\
\text { give effect to the relevant date for determining the ceiling in respect of commercial cable } \\
\text { subscriber has been introduced. The proposed amendment is intended to be a short-term } \\
\text { measure and would be reviewed on the basis of detailed examination as indicated in para } \\
3 \text {. }\end{array}$ \\
\hline 27 Feb. & $\begin{array}{l}\text { Direction to Mobile Service providers in the States of Maharashtra, Tamil Nadu, West } \\
\text { Bengal and Uttar Pradesh not to charge differential tariffs for calls terminating in BSNL } \\
\text { network and other service providers networks }\end{array}$ \\
\hline $23 \mathrm{Feb}$ & $\begin{array}{l}\text { The Telecommunication Interconnection Usage Charges (Sixth Amendment) Regulation } \\
2006 \text { (1 of 2006) } \\
\text { Salient features } \\
\text { - The total amount of ADC shall be reduced to Rs. } 3335 \text { crore and estimated ADC } \\
\text { for BSNL would be Rs. 3,200 crore. Substantial reduction (about 33\%) in the } \\
\text { amount of ADC } \\
\text { - There will not be any ADC on per minute basis on domestic calls. } \\
\text { ADC on International Long Distance traffic shall continue to be on per minute } \\
\text { basis but at a reduced rate of Rs } 1.60 / \text { minute (more than } 50 \% \text { reduction) for } \\
\text { Incoming International calls, this in turn will reduce arbitrage and hence grey } \\
\text { market. ADC on outgoing international calls have been reduced to } \\
\text { Rs.0.80/minute (reduction more than } 65 \% \text { ). } \\
\text { - All licensees of Unified Access Service, Cellular Mobile Telephone Service, } \\
\text { National Long Distance Service and International Long Distance Service shall }\end{array}$ \\
\hline
\end{tabular}




\begin{tabular}{|c|c|}
\hline & 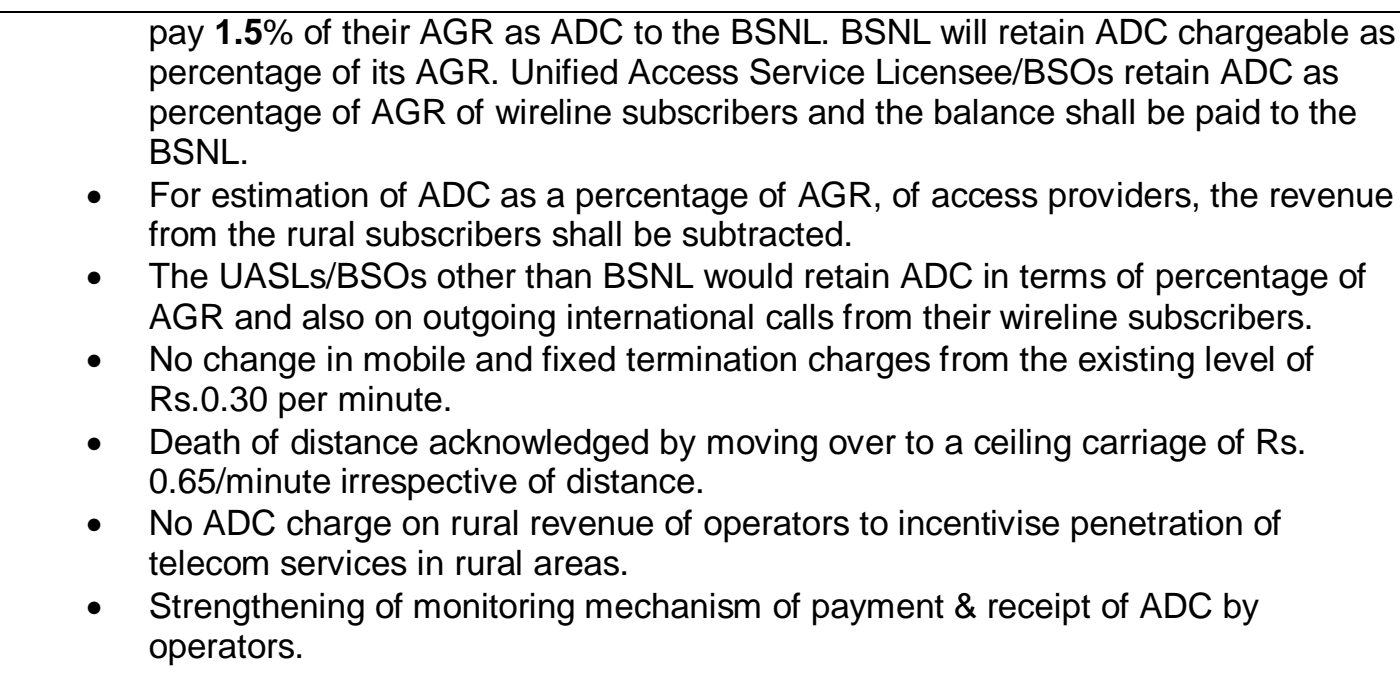 \\
\hline 16 Jan & TRAI issues Consultation Paper on "Tariff Plans with Life Time Validity" \\
\hline 12 Jan & $\begin{array}{l}\text { Consultation Paper on Issues pertaining to Next Generation Networks (NGN) } \\
\text { Issues : - } \\
\text { - } \\
\text { migrate? For which category of stakeholders is NGN relevant? } \\
\text { - Regulatory approaches: Is there need for regulatory initiatives on NGN? Should } \\
\text { there be 'light touch' regulation or are there areas needing more detailed } \\
\text { regulation? What regulatory incentives could help boost benefit from NGN and } \\
\text { reduce risks? Will a move to NGN in rural areas reduce the gap between urban } \\
\text { and rural tele-densities? If yes, how to push NGN to rural India? What } \\
\text { interconnection regime needs to be developed in the NGN context? } \\
\text { - Migration issues: Is there a role for Regulator to ensure smooth migration? }\end{array}$ \\
\hline 2 Jan & $\begin{array}{l}\text { Consultation Paper on Issues relating to Convergence and Competition in Broadcasting } \\
\text { and Telecommunications. }\end{array}$ \\
\hline \multicolumn{2}{|l|}{2005} \\
\hline $2 \mathrm{Dec}$ & $\begin{array}{l}\text { The Register of Interconnect Agreements (Broadcasting and Cable Services) (Second } \\
\text { Amendment) Regulation } 2005 \text { (12 of 2005). TRAI has decided to amend the existing } \\
\text { clause } 6 \text { and make consequential amendments in clause } 5 \text { of the above regulation so as } \\
\text { to enable the Authority to specify a particular procedure in regard to the manner of filing } \\
\text { of data or information; to the form or formats of filing; to the number of copies to be filed; } \\
\text { and, to such other procedural aspects connected and incidental to the filing of details of } \\
\text { interconnect agreements through a simplified process instead of the need to amend the } \\
\text { regulations every time whenever a change in procedure is necessitated. }\end{array}$ \\
\hline $2 \mathrm{Dec}$ & $\begin{array}{l}\text { Draft Regulation on Intelligent Network Services in Multi Operator, Multi Network Scenario } \\
\text { Regulation } 2005\end{array}$ \\
\hline
\end{tabular}




\begin{tabular}{|c|c|}
\hline & $\begin{array}{l}\text { Salient Features : } \\
\text { - All telecom consumers in the country shall have access to Multi-Operator Multi- } \\
\text { Service Intelligent Network (IN) Platform of their choice and no Operator should } \\
\text { be allowed to block his consumers from accessing IN platforms of his choice. } \\
\text { - It shall be the Access Providers' prerogative to deploy their Intelligent Network } \\
\text { (IN). }\end{array}$ \\
\hline $30 \mathrm{Nov}$ & $\begin{array}{l}\text { TRAI issues Direction to Cellular Mobile Service Providers for ensuring Quality of Service } \\
\text { that the Quality of Service parameters, including the level of POI congestion, in its network } \\
\text { should be strictly within the benchmark laid down by the Authority. }\end{array}$ \\
\hline $3 \mathrm{Nov}$ & $\begin{array}{l}\text { TRAI reiterates its Recommendations pertaining to Local Loop Unbundling and Fiscal } \\
\text { Incentives for Broadband. }\end{array}$ \\
\hline 3 Oct & TRAI provides its recommendations on growth of telecom services in rural India \\
\hline 16 Sept & $\begin{array}{l}\text { The Telecommunication Tariff (fortieth Amendment) Order 2005, (7 of 2005) In exercise of } \\
\text { the powers conferred upon it under sub-section (2) of the section } 11 \text { read with section } \\
\text { 11(1)(b)(i) of the Telecom Regulatory Authority of India Act, 1997, the Telecom Regulatory } \\
\text { Authority of India. }\end{array}$ \\
\hline 8 Sept & $\begin{array}{l}\text { The Telecommunication Tariff (thirty ninth Amendment) Order 2005, (6 of 2005). re-fixed } \\
\text { IPLC tariffs. The new ceiling tariffs for three most commonly used capacities i.e. E-1 } \\
\text { (Speed of } 2 \text { Mega Bits Per Seconds), DS-3 (Speed of } 45 \text { Mega Bits Per Seconds) and } \\
\text { STM-1 (Speed of } 155 \text { bits per seconds) }\end{array}$ \\
\hline 1 July & $\begin{array}{l}\text { Regulation on Quality of Service of Basic and Cellular Mobile Telephone Services, } 2005 \\
\text { (11 of 2005) modify some parameters, some deleted and also introduce some new } \\
\text { parameters. }\end{array}$ \\
\hline 24 June & $\begin{array}{l}\text { Consultation Paper on Issues related to Entry Fee \& Annual License Fee for ISP (Internet } \\
\text { Service Provider) License with Virtual Private network (VPN). This consultation paper } \\
\text { presented a scenario in the country as well as international scenario of some other } \\
\text { countries and different types of VPN's \& background about principles of license fee for } \\
\text { various telecom services. }\end{array}$ \\
\hline 6 June & $\begin{array}{l}\text { Consultation paper on Measures to promote competition in International Private Leased } \\
\text { Circuits segment in India; This paper presented a scenario in the country as well as } \\
\text { international scenario of some other countries, and the technical issues \& regulatory } \\
\text { concerns arising out of the current situation. }\end{array}$ \\
\hline
\end{tabular}

